\title{
A UNIDADE EDUCAÇÃO-MÚSICA: EDUCAÇÃO MUSICAL NA TEORIA HISTÓRICO-CULTURAL
}

\author{
Augusto Charan Alves Barbosa Gonçalves ${ }^{1}$ (1) \\ Patrícia Lima Martins Pederiva ${ }^{1}$ (D)
}

\begin{abstract}
RESUMO: O presente artigo é uma pequena síntese de uma Tese de Doutorado que teve como objetivo geral materializar uma educação musical baseada nos princípios extraídos da teoria histórico-cultural de Vygotsky de perspectiva marxista e spinozista, auxiliando a conceber a música como atividade educativa calcada na unidade educação-música voltada para a educação do desenvolvimento da musicalidade das pessoas. Nesse sentido, demonstraremos ao longo deste texto alguns fundamentos da teoria histórico-cultural que se tornaram necessários para a defesa de outro modo possível de educação musical.
\end{abstract}

Palavras-chave: Educação musical. Teoria histórico-cultural. Vygotsky. Spinoza. Marx.

\section{The education-music unity: music education in cultural-bistorical theory}

ABSTRACT: The present article is a small synthesis of a Doctoral Thesis whose general objective was to materialize a musical education based on the principles extracted from Vygotsky's cultural-historical theory of a Marxist and Spinozist perspective, helping to conceive music as an educational activity based on the education-music unity, aimed at the education of developing people's musicality. In this sense, we

${ }^{1}$ Universidade de Brasília, Faculdade de Educação - Brasília, DF, Brasil. E-mails: augustocharan.unb@gmail.com; pat.pederiva@gmail.com

DOI: 10.1590/CC0101-32622019213127 
will demonstrate throughout this text some fundamentals of the cultural-historical Theory that became necessary for the defense of another possible way of music education.

Keywords: Music education. Cultural-historical theory. Vygotsky. Spinoza. Marx.

A fetada diretamente pelos axiomas, escólios, proposições e demonstrações oriundas da ética de Spinoza (2007), que concebe, entre outras coisas, os homens e as mulheres como animais sociais e pelas categorias ontológicas advindas do método histórico-dialético de Marx, que compreendem dialeticamente as coisas por suas totalidades, contradiçóes, transformaçóes e superaçóes, a teoria histórico-cultural do pensador judeu Lev (Leão) Semionovitch (filho de Simeão) Vygotsky ${ }^{1}$ caracteriza-se por estabelecer diversos princípios que possibilitam, de modo singular, outra compreensão do ser humano e da educação. Esta, para o autor soviético, abrange tudo o que é criado por nós. Com efeito, Lev estabelece uma relação de identidade entre a educação e a vida: não há vida propriamente humana fora da educação. Nesse sentido, nada escapa à educação e todo problema que existe na humanidade é primordial e essencialmente uma questáo educativa. Esse fundamento defendido por Semionovitch é, por si só, revolucionário por ir de encontro a toda uma tradição escolástica secular que acredita ser a educação tão somente um sinônimo de escola.

Podemos dizer, sem nenhum medo de errarmos, que a educação musical, em boa medida, alicerça-se na "lógica ou mentalidade escolarizada" (ILLICH, 1985), que, grosso modo, reduz o ser humano ao que é cognitivamente quantificável e monopoliza de forma radical o desenvolvimento musical em espaços restritos que se isolam da vida e que avaliam os estudantes naquilo que supostamente lhes faltam: habilidades, competências, médias, notas etc., como se todas as pessoas, na realidade objetiva, se desenvolvessem musicalmente do mesmo modo e pelos mesmos caminhos (GONÇALVES, 2017; PEDERIVA; TUNES, 2013).

Como bem demonstrou Gonçalves (2017), a essência da educação musical reside na indissociabilidade da unidade dialética educação-música. Em outros termos, quanto mais a música se afasta da vida, isto é, da educação, 
menos educativa ela se torna (GONÇALVES, 2017). Concordamos com Vygotsky (2010a, p. 68, grifo nosso) quando enfaticamente afirma:

Todo meio social artificialmente criado sempre compreenderá vínculos que serão diferentes da realidade concreta e, conseqüentemente, sempre irá manter certo ângulo de divergência com a vida. Daí ser muito fácil concluir que não se deve criar nenhum meio educativo artificial: a vida educa melhor que a escola.

Vida que também forja o professor. Este, para Vygotsky (2010a), é um organizador do espaço social, um educador que regula o ambiente com a intencionalidade de criar condiçóes de possibilidades para que os estudantes possam se desenvolver, imaginar e criar em liberdade. Sendo assim, em uma educação musical de cunho histórico-cultural, o educador musical deve organizar o meio social educativo tendo em vista o compartilhamento das experiências musicais históricas, culturais e particulares das pessoas, favorecendo o amplo desenvolvimento da musicalidade de cada indivíduo-social ao levar em consideração as suas vivências musicais únicas, irrepetíveis e instransponíveis (GONÇALVES, 2017). Em consonância com a teoria de Vygotsky, a relação entre educador musical e estudante se horizontaliza e se edifica na certeza de que ninguém é musicalmente melhor ou pior que ninguém (GONÇALVES, 2017; PEDERIVA; TUNES, 2013).

As experiências musicais são possíveis porque existe uma musicalidade social que antecede nosso nascimento e prossegue após ele. Com efeito, internalizamos as funções psicológicas superiores presentes na cultura em que passamos a existir (VYGOTSKY; LURIA, 1996). Na sociedade humana, desenvolvemos nossa percepção, nossa atençáo voluntária, nossa fala, nossa memória, nosso pensamento conceitual, e é assim que internalizamos a musicalidade social. Esta se torna uma funçáo psicológica superior por exigir não apenas consciência voluntária dos movimentos, do pensamento, dos gestos, mas por se desenvolver na cultura, criando condiçôes de possibilidades para nos relacionarmos com o mundo sonoro.

Táo somente em sociedade, a história ou o desenvolvimento natural-biológico (filogenia) da musicalidade compartilhada com os 
nossos ancestrais se funde com o desenvolvimento cultural-social da musicalidade do indivíduo (ontogenia) em meio as suas experiências musicais (PEDERIVA; TUNES, 2013; GONÇALVES, 2017; GONÇALVES; REZENDE, 2017). Nessa direção, as experiências musicais engendram o processo de desenvolvimento da musicalidade humana e é através dessas experiências que internalizamos aquilo que chamamos de funçôes psicológicas musicais superiores (percepção, atenção, escuta, memória e pensamento musicais etc.).

Desse modo, conforme Gonçalves (2017), uma educação musical que deixe de relevar qualquer uma das três dimensóes das experiências musicais - históricas (de gerações passadas), culturais (alheias) e individuais - , rejeita, na realidade, nossa humanidade, nossa totalidade. Ou seja, é desumana, é padronizadora, é idealista. A educação musical na perspectiva histórico-cultural tem caráter histórico, dialético e se assenta em uma base materialista. Isso é um convite para toda uma educaçáo musical idealista, dualista e abstrata a olhar para a concretude das experiências musicais das pessoas que vivem em um mundo material e real. É um chamamento para se sair do mundo das ideias pequeno-burguesas e ir ao mundo da materialidade, da realidade objetiva que permeia a vida de todos os modos de existência.

Materialidade que permite a concreção das criaçóes humanas. A criação, para Vygotsky (2009), é uma imposição da vida. É uma necessidade. $\mathrm{O}$ autor soviético postula que se não fosse a criação cotidiana, provavelmente não haveria desenvolvimento e nem vida. Se encararmos todas as criaçóes humanas como ferramentas culturais, todas surgiram de uma necessidade. Nada é criado apenas por um impulso interior, muitas das vezes é o meio social que impóe certos limites que culturalmente podem ser superados. Tudo que materialmente vem ao mundo é de ordem da criaçáo humana, até mesmo a cultura. A cadeira que os estudantes sentam nas escolas, antes de ser um objeto, foi um pensamento, uma imaginação que se cristalizou por meio das ferramentas culturais existentes (VYGOTSKY, 2009). Para criar, o ser humano tem, segundo Vygotsky (2009), a necessidade de se adaptar ao meio que o cerca:

Se a vida ao seu redor não o coloca diante de desafios, se as suas reaçôes comuns e hereditárias estão em equilíbrio com o mundo circundante, entáo não haverá base alguma para a emergência da criação. $\mathrm{O}$ ser 
completamente adaptado ao mundo nada desejaria, não teria nenhum anseio e, é claro, não poderia criar. Por isso, na base da criação há sempre uma inadaptação da qual surgem necessidades, anseios e desejos (VYGOTSKY, 2009, p. 40, grifo nosso).

Nas palavras de Vygotsky (2005, p. 5, grifo nosso) fica evidente o seguinte:

As condiçôes sociais, as quais deve integrar a criança, compóem [...] toda aquela atmosfera de inadaptaçáo da criança da qual originam-se todas as forças de seu desenvolvimento; e a existência de obstáculos, que empurram a criança para o desenvolvimento.

"Quanto mais adaptada está a infância em qualquer espécie de animais, tanto menos são as possibilidades potenciais de desenvolvimento e educação", esclarece Vygotsky (1997, p. 45, tradução nossa). Sendo assim, do ponto de vista educativo, Vygotsky implicitamente está dizendo que as atividades educativas devem ser desafiadoras, podendo possibilitar a contínua criação. Com base nas palavras do psiconeurologista e educador russo Zalkind (s.d.) apud Vygotsky (2010a, p. 461), “o criador é sempre da espécie dos descontentes". Concordando com Zalkind (s.d.), Vygotsky (2010a, p. 460) defendia que "um pensamento emitido, um quadro pintado e uma sonata composta nascem de um estado de incômodo dos seus autores".

É por isso que para Vygotsky (2010a, p. 461), "a educação nunca pode limitar-se à razão”. Isto porque, para ele, concordando com Zalkind (s.d.):

O processo pedagógico é a vida social ativa, é a substituição de vivências combativas responsivas, é a luta tensa na qual o professor no melhor dos casos personifica uma grande parte da classe (frequentemente ele é um completo solitário). Todos os seus melhores elementos, toda a experiência do sentir e do pensar, além da vontade, ele utiliza incessantemente em um clima 
de tensa luta social denominada trabalho pedagógico interior. A cadeia das suas insatisfaçóes pessoais, dos incômodos, das aspiraçóes a adaptar-se, das revelaçóes pedagógicas daí decorrentes e das aulas de educação é a mesma cadeia da criação artística [...] o pedagogo-educador não pode náo ser um artista. O objetivismo puro do pedagogo é um absurdo. O educador racional nunca educa (apud VYGOTSKY, 2010a, p. 461, grifo nosso).

De acordo com Vygotsky (2010a, p. 141), “as emoções não podem ser inaceitáveis nem indesejáveis ao pedagogo". O educador tem que, para Vygotsky (2010a), conquistar o sentimento do educando. Não só de intelecto é feito o ser humano...

A velha educação sempre logicizava e intelectualizava o comportamento, resultando daí um terrível "secamento do coraçáo", a completa ausência de sentimento que se tornou traço obrigatório de todos aqueles que passaram por essa educação [...] a emoção não é um agente menor do que o pensamento. $\mathrm{O}$ trabalho do pedagogo deve consistir não só em fazer com que os alunos pensem e assimilem geografia, mas também a sintam [...] as reaçôes emocionais devem constituir a base do processo educativo (VYGOTSKY, 2010a, p. 143-144, grifo nosso).

Como somos, em vida, um corpo, a emoção não se descola dele e por isso mesmo não temos como evitar as afecçóes e os afetos (SPINOZA, 2007). Nesse sentido, querer retirar as emoçóes do corpo é impossível, é dualizar o que é uno. "No existe emoción que sea por naturaleza independiente del cuerpo, que no esté unida a éste" (VYGOTSKY, 2010b, p. 213-214). Quando a educação escolar, em seus processos educativos, retira a emoção, em realidade, ela retira o próprio corpo do processo. E isso é muito grave. Julgamos que só tenha como acabar com as emoçóes se aniquilarem com os corpos. E em certo sentido, a educação musical escolar tem feito isso.

A educação escolar como um todo não devia se fundar na racionalidade seca. Muito pelo contrário! Ao que tudo indica, Vygotsky 
(2010a) militava por uma educação afetiva que pudesse desafiar a todos para a constante criação do novo, para o desenvolvimento, em resumo.

Está claro para qualquer um que quanto mais forte é o incômodo que dá o primeiro impulso ao movimento da alma tanto mais forte é o próprio movimento, que a educação e a criação são sempre trágicas porque partem do "incômodo" e do mal-estar, da desarmonia (VYGOTSKY, 2010a, p. 461).

Desarmonia que engendra o desenvolvimento. Aliás, se existe um "período específico" para o adequado desenvolvimento por meio da educaçáo, este é o da infância. Esta que, para Vygotsky (2010a), caracteriza-se pela "época mais trágica" porque a criança encontra-se, no meio social, em constante adaptação, em constante batalha com o mundo social circundante e consigo mesma.

É justamente por ser a infância a época da educação que ela é a época mais trágica, época da desarmonia e da discrepância do organismo com o meio. A música da educação surge de uma dissonância que ela procura resolver. Quanto mais envelhecemos, quanto mais nos sentimos adaptados e confortáveis na vida tanto menos nos resta espírito criador e mais dificilmente nos prestamos à educação (VYGOTSKY, 2010a, p. 461, grifo nosso).

A criança, em seu desenvolvimento, caracteriza-se por essa "adaptação da experiência hereditária a certo meio social" (VYGOTSKY, 2010a, p. 76). Este autor afirma sem sinal de dúvidas que "o conceito de educação só se aplica à criança, ou seja, ao organismo em crescimento e automudança” (VYGOTSKY, 2010a, p. 77). Mas por quê? O autor explana:

Quando instruímos soldados, ensinamos um jogo, damos algum curso de estenografia ou datilografia deparamos, sem dúvida, com processos psicológicos de natureza educativa, porque em todos esses casos trata-se de elaboração e do estabelecimento de novos sistemas de respostas, de novas formas de comportamento. Para 
efeito de clareza e precisão do assunto, entretanto, seria mais correto falar antes de reeducação no amplo sentido do termo do que educação (VYGOTSKY, 2010a, p. 77, grifo nosso).

Se a palavra educação só se "aplica ao crescimento" e à "mudança autônoma do organismo", como assinala Vygotsky (2010a, p. 77, grifo nosso), então a "educação só pode ser definida como ação planeja$\mathrm{da}$, racional, premeditada e consciente e como intervenção nos processos de crescimento natural do organismo".

Ora, em um adulto, com larga experiência de vida, quase não sobra espaço para outro adulto interferir e orientar em seus processos de autocrescimento orgânico porque estáo em grande parte consolidados, formados, portanto. "Só poderá ter caráter educativo aquela fixação de novas reaçóes que, de uma forma ou de outra, intervenha nos processos de crescimento e os oriente" (VYGOTSKY, 2010a, p. 77). E Vygotsky (2010a, p. 78) encerra alertando: "Logo, nem todos os vínculos que se concluem na criança sáo atos educativos”.

Com o propósito de esclarecer ainda mais o que seria esse tal "ato educativo" para Vygotsky (2010a), faz-se necessário citá-lo em um exemplo que o autor dá levando-se em consideração uma situação hipotética do próprio cotidiano.

Se ao sair de casa eu [Vygotsky] combino com a criança onde vou deixar a chave, com essa atitude estou concluindo um novo vínculo com ela. Mas, se essa relação não tiver nenhuma outra função além de ajudar a criança a procurar a chave, não poderá ser denominada educativa do ponto de vista psicológico. Por conseguinte, tudo o que fazemos com a criança é educação [...] (VYGOTSKY, 2010a, p. 78, grifo nosso).

Vygotsky faz uma clara distinção entre os termos educação e reeducação (esta ocorre até o último momento de vida do ser humano). Depreende-se que quando algum adulto aprende um jogo novo ou uma nova atividade como a de pilotar um avião, por exemplo, não é uma educação propriamente dita, e sim uma reeducação. Sendo coerente com a perspectiva histórico-cultural, a educação musical, nesse sentido, ao 
estudar a educação do desenvolvimento da musicalidade do adulto, deve cambiar a sua terminologia para reeducação musical. Caso contrário, no entendimento proporcionado pela teoria de Vygotsky, o termo permanecerá inadequado, cientificamente e pedagogicamente impreciso. Além disso, tal concepção de educação aumenta a responsabilidade pedagógica dos educadores musicais ao terem em mente que para a criança, do ponto de vista musical, tudo é educação musical.

Para Vygotsky (2005, p. 8, grifo nosso), pensador que acreditava que "a perspectiva psicológica do futuro é a possibilidade teórica da educação", diz o seguinte também:

A criança por sua natureza revela-se sempre incompleta em comparação com o adulto; sua posição, desde o início, dá razáo para o desenvolvimento nela de sentimento de fraqueza, insegurança e dificuldade. A criança, durante longos anos, permanece inadaptável para a existência independente e nesta inadaptação e incômodo da infância está a raiz do seu desenvolvimento. A infância é a época de insuficiências e compensaçóes pela vantagem, ou seja, pela conquista de posições com relação ao social. No processo desta conquista o ser humano como um determinado biótipo transforma-se em ser humano como tipo social, um organismo animal constitui-se numa personalidade humana. $O$ dominio deste processo social natural é chamado de educação (VYGOTSKY, 2005 , p. 8 , grifo nosso).

Sendo assim, a constante adaptação das crianças e dos adultos aos desafios impostos pelo meio social normalmente impele o desenvolvimento em suas diversas modalidades. Por essa causa, Vygotsky (2004, p. 45) chega à conclusão de que a adaptação "é a lei fundamental e universal do desenvolvimento e da vida no organismo". Adaptação enquanto processo dinâmico oriundo de constantes inadaptaçôes movidas por conflito e superação (não garantida) de desafios impostos pelas relaçóes no e com o mundo biológico, histórico e cultural.

A lei do desenvolvimento é única, mas varia de diversas formas, como demonstra Vygotsky (1997) em seu livro Fundamentos de 
Defectología. Aqui reside o seu princípio ético e filosófico: a possibilidade que existe de todos se desenvolverem. Nessa direçáo, podemos assegurar que as pessoas se desenvolvem musicalmente de distintas maneiras e que cada indivíduo se desenvolve musicalmente de modo singular, único.

"A criança cujo o desenvolvimento está complicado por causa do defeito não é simplesmente uma criança menos desenvolvida em relação às outras, mas desenvolvida de outro modo", defende Vygotsky (1997, p. 12, grifo do original, traduçáo nossa). $\mathrm{O}$ autor demonstra que mesmo pessoas com defeitos biológicos, vistas muitas vezes como incapazes pela sociedade ou impossibilitadas de se adaptarem ao mundo, podem se desenvolver tanto ou mais que as pessoas sem defeitos biológicos, adquirindo, ao longo da vida, comportamentos complexos (VYGOTSKY, 1997), inclusive de ordem musical. A educação musical de base histórico-cultural respalda cientificamente que pessoas com defeitos biológicos podem (e de fato) se desenvolvem musicalmente como quaisquer outros individuos-sociais.

Ao que parece, o comportamento musical é forjado nas reaçóes musicais cotidianas. Para Vygotsky (2010a, p. 78), reação é "um complexo processo de inter-relaçáo do homem com o mundo, determinado pela adaptação. O comportamento é a forma superior de adaptação ao meio".

O comportamento do homem é formado pelas peculiaridades e condiçôes biológicas e sociais do seu crescimento. O fator biológico determina a base, o fundamento das reaçóes inatas, e o organismo não tem condição de sair dos limites desse fundamento, sobre o qual se erige um sistema de reaçóes adquiridas. Nesse caso aparece com plena evidência o fato de que esse novo sistema de reaçóes é inteiramente determinado pela estrutura do meio onde cresce e se desenvolve o organismo. Por isso toda educação é de natureza social, queira-o ou não (VYGOTSKY, 2010a, p. 63, grifo nosso).

A educação musical calcada na unidade dialética educação-música é assumidamente de natureza social e se propóe enquanto tal a guiar a educação do desenvolvimento da musicalidade humana por meio de processos educativos de inadaptaçóes musicais no sentido de superar e transformar as reaçóes musicais incondicionadas em culturalmente condicionadas (GONÇALVES, 
2017). Em outras palavras, ela intenciona criar condiçóes de possibilidades para a internalização da musicalidade social (ou das funçóes musicais psicológicas superiores) pelos indivíduos que, como quaisquer seres humanos, possuem musicalidade e são musicais (PEDERIVA; TUNES, 2013).

Diante do que foi exposto, podemos afirmar que conceber uma educação musical que esteja de acordo com os princípios (neste escrito mencionamos alguns poucos) advindos da teoria histórico-cultural de Vygotsky é primar, dentre muitas outras coisas, pela suprema importância do social no processo de constituição musical da pessoa, ou seja, de suas emoçôes, experiências, criações e imaginações musicais. Mais ainda, é uma educação musical que atribui ao professor a função de organizador do espaço social educativo. Sendo assim, o educador musical não é nem um facilitador e muito menos um mediador. Isso porque, conforme demonstra Vygotsky (1995, p. 94), as relaçóes sociais são mediadas pelos signos (primordialmente psicológicos, internos) e pelas ferramentas materiais (externas ao próprio corpo) criadas pelos seres humanos. Dessa maneira, na perspectiva histórico-cultural de Vygotsky, o professor (como qualquer outro indivíduo social) pode utilizar (e de fato usa) diversas ferramentas e signos. Entretanto, o professor não é uma coisa ou um objeto mediador, ao menos do ponto de vista cientificamente pedagógico, ele não deveria ser visto ou compreendido desse modo inadequado. Tanto professores quanto estudantes são seres de relaçóes. $O$ ato pedagógico é relacional.

\section{REFERÊNCIAS}

GONÇALVES, A.C.A.B. Educação musical na perspectiva histórico-cultural de Vigotski: a unidade educação-música. 2017. 277f. Tese (Doutorado em Educação) - Programa de Pós-Graduação em Educação, Faculdade de Educação, Universidade de Brasília, Brasília, 2017.

GONÇALVES, A.C.A.B.; REZENDE, M.S. Educação musical na perspectiva histórico-cultural: quando musicalidade e música se entrelaçam na vivência do indivíduo no mundo social. In: PEDERIVA, P.L.M.; PAULA, T.R. de; NASCIMENTO, D.L. do (orgs.). O Ato Estético: conversas sobre educação, imaginação e criação na perspectiva histórico-cultural. Curitiba: CRV, 2017.

ILLICH, I. Sociedade sem escolas. Tradução de Lúcia Mathilde Endlich Orth. Petrópolis: Vozes, 1985. 
PEDERIVA, P.L.M; TUNES, E. Da atividade musical e sua expressão psicológica. Curitiba: Prismas, 2013.

SPINOZA, B. Ética. Tradução e notas de Tomaz Tadeu. Edição bilíngue. Belo Horizonte: Autêntica, 2007.

VYGOTSKY, L.S. Fundamentos de defectología. Madri: Visor, 1997. (Obras Escogidas, V).

. Imaginação e criação na infância: ensaio psicológico. São Paulo: Ática, 2009. - Psicologia Pedagógica. Tradução do russo e introdução de Paulo Bezerra. 3. ed. São Paulo: WMF Martins Fontes, 2010a.

- Problemas del desarrollo de la psique: historia del desarrollo de las funciones psíquicas superiores. Madri: Visor, 1995. (Obras Escogidas, III).

Sobre a questão da dinâmica do caráter infantil. Tradução de Zoia. Teias, Rio de Janeiro, ano 6, n. 11-12, jan./dez. 2005.

. Teoría de las emociones: estudio histórico-psicológico. Madri: Akal, 2010b. . Teoria e Método em Psicologia. São Paulo: Martins Fonte, 2004.

VYGOTSKY, L.S.; LURIA, A.R. Estudos sobre a história do comportamento humano: o macaco, o primitivo e a criança. Tradução de Lólio Lourenço de Oliveira. Porto Alegre: Artes Médicas, 1996.

\section{NOTA}

1. São variadas as formas de escrever o nome desse autor bielorrusso: Vygotsky, Vygotski, Vigotsky, Vigotskii, Vigotskji, Wygotski, Vigotskji, Vigôtski etc.

Recebido em 24 de agosto de 2018.

Aprovado em 11 dezembro de 2018. 